\title{
Değişim Yorgunluğu Ölçeği Türkçe Versiyonunun Geçerlilik ve Güvenirlik Çalışmass: Sağlık Çalışanları Örneği
}

\author{
Validity and Reliability Study of the Turkish Version of the Chanğe Fatiğue Scale: A Case of Healthcare Employees
}

\section{Erhan Ekingen, Ahmet Ylldız}

Batman Üniversitesi Sağlık Yüksek Okulu Sağlık Yönetimi Bölümü, Batman, Türkiye

Correspondence:

Erhan EKINNGEN

Batman Üniversitesi Sağllk Yüksek Okulu Sağlık Yönetimi Bölümü,

Batman, Türkiye

e-mail:erhan.ekingen@batman.edu.tr

\section{Özet}

Sağlık hizmet sunumunda kullanılan teknolojilerin, malzemelerin, tedavi yöntemlerinin ve süreçlerinin sürekli gelişmesi ve hızla değişmesi, sağlık sistemlerinde yașanan dönüșümler ve çalıșma koșullarında yașanan değișimler çalıșanları değișime karșı yorgun kılabilir. Bu durum, çalıșan davranışlarını ve sunulan hizmetin kalitesini etkileyebilir. Calıșanların değișim yorgunluğu düzeyinin bilinmesi, yapılacak değișim süreçlerindeki planlamalarda hangi stratejilerin izleneceğinin belirlenmesine katkı sağlayabilir. Ancak yapılan literatür taramasında değişim yorgunluğu ile ilgili kullanılan Türkçe değerlendirme araçlarının ve sağlık çalışanları ile yapılan çalışmaların sınırlı olduğu görülmüştür. Bu çalıșmanın amacı, sağlık çalışanları üzerinde uygulanan Değișim Yorgunluğu Ölçeği Türkçe versiyonunun geçerlilik ve güvenirliğin test etmektir. Araştırma, bir kamu hastanesinde görev yapan 193 sağlık çalışanı üzerinde yapılmıştır. Ölçeğin güvenirliğini değerlendirmek için Cronbach alfa katsayısına ve Spearman-Brown güvenirlik katsayına bakılmıştır. Ölçeğin yapı geçerliliğini test etmek için açıklayıcı ve doğrulayıcı faktör analizleri yapılmıştır. Ayrıca ölçek, dil ve kapsam geçerliliği açısından da değerlendirilmiştir. Değişim Yorgunluğu Ölçeğinin dil ve kapsam geçerliliğine sahip olduğu belirlenmistir. Ölçeğin Cronbach alfa katsayısı ,901, Spearman-Brown Güvenirlik katsayıs ise, 84 olarak hesaplanmış olup, ölçeğin güvenilir olduğu tespit edilmiştir. Yapılan doğrulayıcı faktör analiz sonuçlarına ( $\chi 2 / \mathrm{df:}$ : 2,23; RMSA: ,08; CFI: ,98; IFI: ,98; GFI: ,97; RMR: ,03 ve NFI: ,97) göre ölçeğin tek faktörlü olarak doğrulandığı görülmüştür. Araştırma sonucunda elde edilen bulgulara göre, tek boyutlu bir yapıda olan Değişim Yorgunluğu Ölçeği’nin Türkçe versiyonu geçerli ve güvenilirdir.

Anahtar Kelimeler: Değişim Yorgunluğu Ölçeği; Geçerlilik ve Güvenirlik, Sağlık Çalışanları

\section{Abstract}

The continuous development and rapid change of technologies, materials, treatment methods and processes used in health service delivery transformations in health systems and changes in working conditions can make employees tired of change. This can affect employee behavior and the quality of service provided. Knowing the change fatigue level of the employees can contribute to which strategies to be followed in the planning of the change processes to be made. However, in the literature review, it was observed that the Turkish assessment tools used for change fatigue and the studies conducted with healthcare employees were limited. The aim of this study is to test the validity and reliability of the Turkish version of the Change Fatigue Scale carried out on the healthcare employees. The research was conducted on 193 healthcare workers working in a public hospital. Cronbach alpha coefficient and Spearman-Brown reliability coefficient were examined to evaluate the reliability of the scale. Exploratory and confirmatory factor analyzes were conducted to test the construct validity of the scale. In addition, the scale was evaluated in terms of language and content validity. It has been determined that the Change Fatigue Scale has language and content validity. The Cronbach alpha coefficient of the scale was calculated as .901 and the Spearman-Brown reliability coefficient as .84 and the scale was found to be reliable. According to the confirmatory factor analysis results ( $\chi 2$ /df: 2.23; RMSA: .08; CFI: .98; IFI: .98; GFI: .97; RMR: .03 and NFI: .97), it was observed that the scale was confirmed with a single factor. According to the findings obtained as a result of the research, the Turkish version of the Change Fatigue Scale, which has a one-dimensional structure, is valid and reliable.

Keywords: Change Fatigue Scale; Validity and Reliability; Healthcare Employees

Received 07.05.2021 Accepted 25.06.2021 Online published 25.06.2021 


\section{Giriș}

İçinde yaşadığımız dönem, en iyi şekilde değişim zamanı olarak tanımlanabilir (1). Organizasyonlarda yaşanan değişimlerin altında yatan birçok neden vardır. Bunların arasında, teknolojik gelişmeler, mal ve hizmet talep edenlerin beklentilerindeki değişimler, rekabet koşulları, organizasyonların ulusal veya uluslararası pazarlara yönelim çabası, maliyet azaltma, süreç iyileștirme, merkezi yönetimin beklentileri, örgütün etkinliğini ve verimliğini artırma çabaları ile ilgili birçok neden yer alır. Organizasyonlarda gerçekleşen değişimler, içsel bir istek veya değişme ihtiyacından ziyade, öncelikle diş baskı nedeniyle sürekli bir değişme eğilimindedir (2).

Değişim, organizasyonlar için bir yaşam biçimi haline gelmiştir (2). Organizasyonlarda yaşanan değimler organizasyon teorisi ve yönetiminde de merkezi bir konuma gelmiştir (3). Merkezi otorite veya üst kademe yöneticiler tarafindan hayata geçirilen değişimlerin sıklığı, çalışanların bu değişimlere uyumunu çoğu zaman zorlaştırmaktadır. Hayata geçirilen değişimlerin süreçleri tamamlanmadan veya yapılan faaliyetlerin sonuçları değerlendirilmeden yeni değișimlerin hayata geçirilmeye çalışılması çalışanları bu değişimlere karşı yorabilmektedir.

Üretim faktörleri arasında yer alan insan kaynağının tutum ve davranışları örgüt çıktıları üzerinde önemli bir etkiye sahiptir. Ayrıca hizmet sektöründe insan kaynağının daha etkin rol alması bu etkiyi daha fazla arttırmaktadır. Organizasyonlar için değişim, bir hayatta kalma mücadelesi olarak görülse de, değişimlerin planlı bir şekilde gerçekleşmesi, sonuçlar izlenmeden yeni değişimlere kapı aralanması çalışanların değişim süreçlerindeki tutum ve davranışlarını olumsuz etkileyebilmektedir. $\mathrm{Bu}$ nedenle değişim ile elde edilmek istenen başarının elde edilmesinde, çalışanların değişime karşı olan yorgunluğu bir engel olabilir.

Değişim yorgunluğu kavramı alan yazında; girişim yorgunluğu (initative fatigue), yenilik yorgunluğu (innovation fatigue), reform yorgunluğu (reform fatigue), tekrarlayan değişim sendromu (repetitive change syndrom) ve değişim bıkkınlığı (being tired of change) gibi terimlerle de karşımıza çıkmaktadır $(4,5,6,7,8,9)$. Zink, Steimle ve Schroder, (2008) değişim yorgunluğunu, ilişkisiz çok fazla değişim girişimi sonucu çalışanlarda ortaya çıkan değişime karş1 olumsuz bir alg1 şeklinde tanımlamıştır (10). Bir diğer tanımda da benzer şekilde değişim yorgunluğunun, organizasyonda gereğinden fazla değişiklik yaşandığına yönelik çalışanlarda oluşan olumsuz bir algı olduğu belirtilmiştir (8). Lyle ve diğerleri (2014) ise değişim yorgunluğunu çalışanın, değişim girişiminden kaynaklı olumsuz iş deneyimleri ve örgüt içerisinde çok fazla değişim süreçlerini yaşanmasından dolayı değişime karşı isteksizlik ve bıkkınlık olması şeklinde tanımlamıştır (9). Buchanan ve arkadaşları (2005) değişim yorgunluğunun, değişim tetikleyicilerin hızlı ve sürekli olmasının çalışanda yarattığı olumsuz alg1 durumu, McMillan ve Perron, (2013) ise işyerindeki hızlı ve sürekli değişim ile ilişkili ezici stres, bitkinlik ve tükenmişlik durumu olduğunu ifade etmişlerdir $(11,12)$. Bu tanımlar ve açıklamalardan yola çıkarak değişim yorgunluğu, organizasyondaki değişimlerin çalışanlar tarafindan gereğinden fazla veya aşırı görülmesi, değişimlerin hiç son bulmayacağ 1 , değişimlerin iyileşme ve yenilik getirmeyeceği, değişimin bir parçası olmanın anlamsız olacağı algısı ile çalışanlarda meydana gelen değiş̧ime karşı stres, bitkinlik ve tükenmişlik hissi şeklinde tanımlanabilir.

Sağlık sektörü, değişimin en fazla görüldüğü sektörler arasında yer almaktadır (13). Tibbi teknolojilerdeki gelişmelerden kaynaklanan uygulama değişiklikleri, yeni bilgi ve iletişim sistemlerinin iş akışlarındaki değişiklikler ve artan sağlık hizmetleri talebine yanıt olarak altyap1 geliştirme çabaları sağlı kuruluşlarının sürekli bir değişim içinde olmasına neden olmaktadır (13). Sağlık kurumlarında, çalışanların değişim algısı aşırı görünüyorsa, bu değişim hızı, işgücü ve sağlık hizmetleri organizasyonu için istenmeyen sonuçlara yol açabilir. Bu değişimler zamanla çalışanlar üzerinde yorgunluk ve tükenmişlik 
semptomları üreterek, ekip bağlılı̆̆ın, personel sağlığını ve hasta bakım kalitesini etkileyebilir $(13,14,15) . \mathrm{Bu}$ nedenle çalışanların değişime karşı algılarının bir başka ifade ile değişim yorgunluk düzeylerinin bilinmesi, değişim süreçleri ile ilgili planlamaların (ne zaman, hangi çalışan grubu ile kimlerle vb.) doğru bir şekilde yapılmasına ve ayrıca çalışan sağlığını ve hasta bakım kalitesini iyileştirmek ve değerlendirmek için atılacak adımlara katkı sağlayabilir.

Yapılan literatür taramasında değişim yorgunluğunu değerlendirmek için sınırlı sayıda Türkçe değerlendirme araçlarının olduğu (1) ve sağlı kuruluşlarında ise araştırmada kullanılan ölçeğe ait geçerlilik ve güvenirlik çalışmasının yapılmadığı görülmüştür. Sağlık kurumları dinamik yapılardır. Gelişen teknoloji ve kaliteli hizmet beklentisi sağllk sistemlerinde ve hizmeti sunum şekillerinde değişimi zorunlu kılmaktadır. Bu değişim, sağlık çalışanlarının görev ve sorumluluklarında da değişimi meydana getirmektedir. Sağlık çalışanlarının değişime çok fazla maruz kalması değişim yorgunluğuna sebep olabilir. Bu durum sağlık çalışanlarının hizmet sunumunda performansının düşmesine neden olabilir ve hizmet sunum kalitesini etkileyebilir. $\mathrm{Bu}$ yüzden sağlık çalışanlarının değişim yorgunluğu düzeyinin değerlendirilmesi önemlidir. Bunun için değişim yorgunluğu ölçüm araçlarına ihtiyaç duyulmaktadır. Bu çalışmanın amacı, sağlık çalışanları üzerinde Değişim Yorgunluğu Ölçeği'nin Türkçe geçerlilik ve güvenirliğini test etmektir.

\section{Gereç ve Yöntemler}

\section{Veri Toplama Aract}

Araştırmada, Bernerth ve diğerleri (2011) tarafından geliştirilen ve tek boyuttan oluşan değişim yorgunluğu ölçeği kullanılmıştır. Altı maddeden oluşan ölçek, 7'li Likert tipi (1 kesinlikle katılmiyorum -7 kesinlikle katılıyorum) bir ölçektir. Değişim Yorgunluğu Ölçeği, işyerinde talep edilen değişim ile çalışanın değişime karşı algısı arasındaki etkileşimin duygusal, bilișsel ve sosyal sonuçlarını ele alır (8).

\section{Ölçeğin Türkçe Uyarlaması}

Ölçek, iki dile (İngilizce, Türkçe) hâkim iki akademisyenin birlikte çalışması ile Türkçeye çevrilmiştir. Bir başka akademisyen tarafından Türkçe metin İngilizce metne tekrar çevrilmiştir. İngilizce ilk metin ile son metin arasında farklılığın olmadığ 1 görülmüştür. Türkçeye çevrilen ölçek asıl uygulamadan önce 15 kişi üzerinde uygulanmıştır. Ön uygulamada katılımcıların yanında bulunulmuş ve ölçek maddelerinde anlaşılmayan bir hususun olup olmadığ 1 değerlendirilmiştir. Sonuç olarak, ölçeğin Türkçe çevirisinin İngilizce versiyonu ile tutarlı olduğu gözlendiğinden ve ölçek maddelerinin anlaş1lır olduğu belirlendiğinden ölçeğin dil bakımından geçerli olduğuna karar verilmiştir.

\section{Evren ve Örneklem}

Yapısal eşitlik model (YEM) temelli araştırmalar için gerekli örneklem büyüklüğünün belirlenmesinde; tahmin edilecek parametre sayının en az 10 katı örneklem büyüklüğüne ulaşılması beklenir (16). Araştırma modelinde toplamda 12 tahmin edilecek parametre ([tahmin edilecek hata varyans1: 6] + [tahmin edilecek faktör yükü: 5] + [tahmin edilecek örtük değişken: 1] = 12) bulunmaktadır. Buna göre parametre sayısı açısından en az $120(12 \times 10=120)$ kişiye ulaşılması gerekmektedir. Ayrıca YEM temelli araștırma için gerekli olan örneklem büyüklüğünün en az 150 olması beklenmektedir (16).

Araştırmanın evreni, bir kamu hastanesinde aktif görevde ve daimi kadroda yer alan 356 çalışandan oluşmaktadır. Araştırmada herhangi bir örneklem seçilmemiş olup, araştırmaya katılmayı kabul eden tüm çalışanlar araştırmaya dâhil edilmiştir. Araştırma, araştırmaya katılmayı kabul eden 193 (\%54,2) sağlık çalışanı üzerinde yapılmıştır. Sonuç olarak YEM temelli araștırma için gerekli minimum örneklem büyüklügünün üzerinde ve araştırmada kullanılan parametre sayısının 10 katından fazla örneklem büyüklüğüne ulaşılmıştır. Araştırma, Batman Eğitim ve Araştırma Hastanesinden 15.12.2020 tarih ve 261 say1l Etik Kurul izni alındıktan sonra 15 Şubat-29 
Mart $2021 \quad$ tarihleri arasında gerçekleştirilmiştir.

\section{Istatistiksel analiz}

Veriler "SPSS 20,0" ve "AMOS 21" yazılımları kullanılarak analiz edilmiştir. Değişim Yorgunluğu Ölçeği'nin geçerliliği, kapsam ve yap1 geçerliliği yöntemleri kullanılarak değerlendirilmiştir. Çalışmada, ölçeğin kapsam geçerliliği için uzmanlara danışılmıştır. Yapı geçerliliğini test etmek için açıklayıcı ve doğrulayıcı faktör analizleri (DFA) yapılmıştır. Ölçeğin faktörlenebilirliliğini test etmek için Bartlett'in küresellik testi, örneklem yeterliliğini ölçmek için Kaiser-Meyer-Olkin (KMO) testi yapılmıştır. Ölçeğin güvenirlik analizi için
Cronbach's alfa ve Spearman-Brown güvenilirlik katsayıları kullanılmıştır.

\section{Bulgular}

\section{Katılımcılara Ait Mesleki ve Demografik Bulgular}

Katılımcilara ait demografik ve mesleki özellikler tablo halinde verilmiştir (Tablo 1). Araştırmaya katılanların yarısından fazlası kadınlardan $\quad(\% 64,2) \quad$ oluşmaktadır. Araştırmaya katılanların yaş ortalaması 34,5 'tir. Katılımcıların büyük bir çoğunluğu $(\% 59,6)$ nöbet usulü çalışmaktadır. Katılımcıların çoğunluğunun lisans $(\% 39,9)$ ve ön lisans $(\% 37,3)$ mezunu olduğu görülmüştür. Kurumda ortalama çalışma süreleri ise 7,3 yıldır.

Tablo 1. Demografik ve Mesleki Özellikler (N=193)

\begin{tabular}{|c|c|c|c|c|c|c|}
\hline Değişkenler & Sayı & Yüzde & Değișkenler & Sayı & Yüzde & $\begin{array}{c}\text { Ortalama } \\
\pm \mathrm{SS}^{\mathrm{a}}\end{array}$ \\
\hline Cinsivet & & & $\underline{\text { Yas }}$ & & & $34,5 \pm 6,8$ \\
\hline Kadın & 124 & 64,2 & $\overline{30 \leq}$ & 65 & 33,7 & \\
\hline Erkek & 69 & 35,8 & $31-40$ & 94 & 48,7 & \\
\hline Ë̆itim Düzeyi & & & $41 \geq$ & 34 & 17,6 & \\
\hline Lise & 34 & 17,6 & Kurum Calıșma Süresi & & & $7,3 \pm 5,1$ \\
\hline Ön lisans & 72 & 37,3 & $5 \leq$ & 64 & 33,2 & \\
\hline Lisans & 77 & 39,9 & $6-10$ & 84 & 43,5 & \\
\hline Lisansüstü & 10 & 5,2 & $11 \geq$ & 45 & 23,3 & \\
\hline Görev & & & Calıșma Sekli & & & \\
\hline Sağlık* & 107 & 55,5 & Gündüz & 78 & 40,4 & \\
\hline Destek** & 86 & 44,6 & Nöbet & 115 & 59,6 & \\
\hline
\end{tabular}

\section{Ölçeğin Kapsam Geçerliliği}

Ölçeğin kapsam geçerliliğini sınamak için yedi akademisyen görüşüne başvurulmuştur. Ölçeklerin kapsam geçerliliği için minimum beş uzman görüşü yeterli görülmektedir (17). Bir maddenin ölçekte yer almasına karar vermek için uzmanların yarısından fazlasının ilgili madde için "gerekli" olduğunu ifade etmesi yeterlidir $(17,18,19)$. Araştırmada görüşlerine başvurulan akademisyenler her bir maddeye ilişkin görüşlerini "gerekli", "yararlı ancak gerekli değil" ve "gerekli değil" şeklideki bir derecelendirme ile belirtmişlerdir. Dört akademisyen maddelerin tamamının gerekli olduğunu, bir akademisyen
DY-3 maddesinin yararl,, ancak gerekli olmadığını, iki akademisyen ise DY-3 ve DY5 soruları için yararlı ancak gerekli olmadığını belirtmişlerdir. Akademisyenlerin yarısından fazlası tüm maddeler için "gerekli" şeklinde değerlendirme yaptıklarından araştırmada kullanılan ölçeğin kapsam geçerliliğine sahip olduğu sonucuna varılmıştır.

\section{Ölçeğin Yapı Geçerliliği ve Güvenirliği}

Ölçeğin güvenirliğini test etmek için Cronbach alfa katsayısina ve SpearmanBrown güvenirlik katsayına bakılmıştır. Ölçeğin Cronbach alfa katsayısı ,901'dir. Spearman-Brown Güvenirlik katsayısı (ikiye 
bölünmüş yöntem) ise ,84'tür. Çalışmada ayrıca Değișim Yorgunluğu Ölçeği'ne ait korelasyon ve madde toplam istatistiklerine bakılmıştır. Ölçek maddelerine ait korelasyon katsayıları ve madde-toplam istatistik analiz sonuçları tablo halinde verilmiştir (Tablo 2; Tablo 3). Analiz sonuçlarına göre maddeler arasındaki korelasyon katsayılarının,458 ,789 arasında olduğu, toplam korelasyon katsayılarının ise ,604-,811 arasinda ve ,90'nın altında olduğu görülmüştür. Madde çıkarımı sonrası Cronbach alfa katsayılarının ,866-,900 arasında olduğu görülmektedir. Madde toplam korelasyonunun yüksek olması testin iç tutarlılığının yüksek olduğunu göstermektedir (20). Conbach alfa katsayısının ve Spearman-Brown güvenirlik katsayısının 0,80 üzerinde olması ölçeğin yüksek güvenirliğe sahip olduğu şeklinde değerlendirilmektedir (18). Buna göre ölçeğin yüksek güvenirliğe sahip olduğu ve ölçeğin iç tutarlılığının yüksek olduğu söylenebilir.

Tablo 2. Değişim Yorgunluğu Ölçek Maddelerine Ait Korelasyon Katsayıları

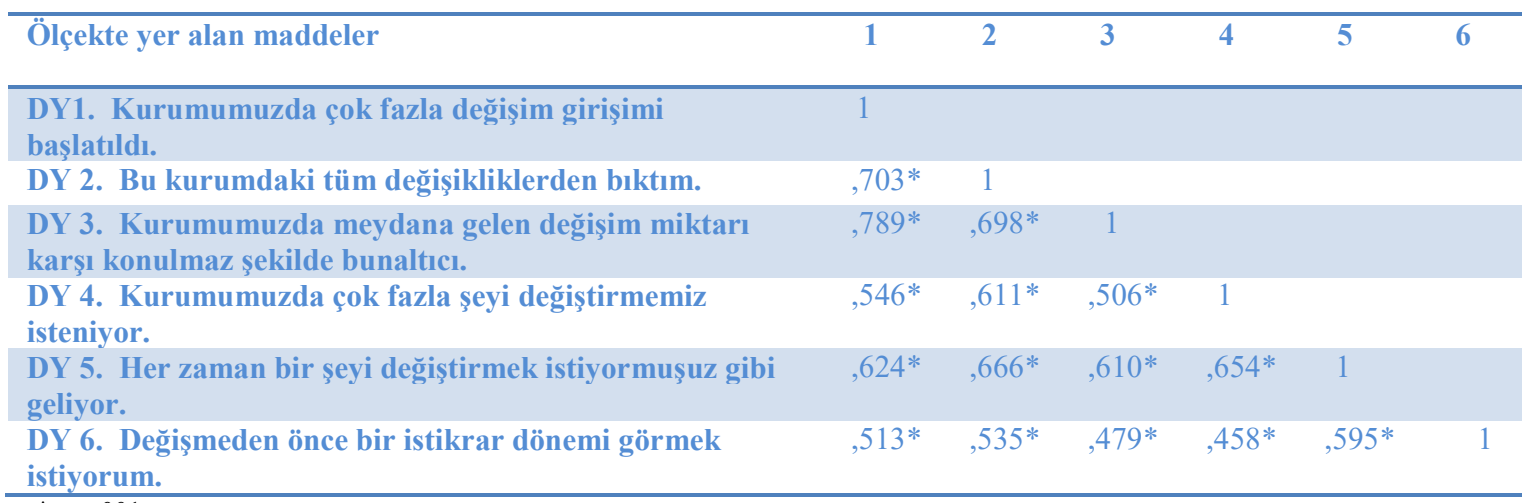

$* \mathrm{p} \leq, 001$

Tablo 3. Madde-Toplam İstatistikleri

\begin{tabular}{ccccc}
\hline Maddeler & $\begin{array}{c}\text { Madde } \\
\text { Silindiğinde } \\
\text { Ölçek } \\
\text { Ortalaması }\end{array}$ & $\begin{array}{c}\text { Madde } \\
\text { Silindiğinde } \\
\text { Ölçek } \\
\text { Varyansı }\end{array}$ & $\begin{array}{c}\text { Toplam } \\
\text { Korelasyon }\end{array}$ & $\begin{array}{c}\text { Çoklu } \\
\text { Korelasyonun } \\
\text { Karesi }\end{array}$ \\
DY 1 & 20,424 & 22,746 &, 804 &, 724 \\
Cronbach's \\
aY 2
\end{tabular}

Ölçeğin yap1 geçerliliğini test etmek için açıklayıcı ve doğrulayıcı faktör analizleri yapılmıştır. Değişim Yorgunluğu Ölçeği’nin betimsel istatistikleri, güvenilirlik katsayıları ve açıklayıcı faktör analiz sonuçları tablo halinde verilmiştir (Tablo 4). Faktör analizi için veri yapısının uygunluğunu ve faktörlenebilirliğini belirlemek üzere yapılan testlerde KMO katsayısı ,88 olarak belirlenmiştir ve Bartlett'in küresellik testi sonucu anlaml $1 \quad(\chi 2=714,93 ; \quad \mathrm{p}<, 001)$ bulunmuştur. Faktör sayısını belirlemek için, yamaç eğim grafiğinden yararlanılmıştır (Şekil 1). Şekil 1 incelendiğinde; özdeğeri
1 'den büyük bir faktörün olduğu, sonraki faktörlerin özdeğerinin 1'in altında olduğu ve çok az değiştiği görülmektedir. Ölçeğin 1. faktör öz değeri: 4,038'dir. Tek faktörlü yap1 toplam varyansin \%67,29'luk kisminı açıklamaktadır. Toplam varyansı açıklama oran1 sosyal bilimlerde, ,40-,60 arasinda yeterli kabul edilir (18). Faktör yükleri incelendiğinde maddelerin faktör yüklerinin ,71-,87 arasında değiştiği ve tüm maddelerin birinci faktöre yüksek düzeyde yüklenebildiği görülmüştür. Sağlık çalışanlarının değişim yorgunluğu düzeylerine bakıldığında ölçeğe verilen yanıtların ortalama puanlarının (7'li 
Likert üzerinden) $4,13 \pm 1,03$ olduğu görülmüştür. En yüksek ortalamaya sahip maddenin "Kurumumuzda çok fazla değişim girişimi başlatıldı" $(4,66 \pm 1,37)$ maddesi olduğu; en düşük ortalamaya sahip maddenin ise "Her zaman bir şeyi değiştirmek istiyormuşuz gibi geliyor" $(3,80 \pm, 97)$ maddesi olduğu belirlenmiştir.

Tablo 4. Değişim Yorgunluğu Ölçeği’nin Betimsel İstatistikleri, Güvenilirlik Katsayıları ve Açıklayıcı Faktör Analiz Sonuçları

\begin{tabular}{lccc}
\hline Ölçekte yer alan maddeler & $\begin{array}{c}\text { Ortalama } \\
\pm \text { SS }\end{array}$ & $\begin{array}{c}\text { Faktör } \\
\text { Yüküi }\end{array}$ & $\begin{array}{c}\text { Ortak } \\
\text { Varyans }\end{array}$ \\
\hline DY 1. Kurumumuzda çok fazla değişim girişimi başlatıldı. & $4,66 \pm 1,37$ &, 87 &, 76 \\
DY 2. Bu kurumdaki tüm değişikliklerden bıktım. & $4,08 \pm 1,29$ &, 88 &, 77 \\
DY 3. Kurumumuzda meydana gelen değişim miktarı karşı konulmaz & $4,39 \pm 1,26$ &, 83 &, 69 \\
şekilde bunaltıc1. & $3,87 \pm 1,1$ &, 76 &, 58 \\
DY 4. Kurumumuzda çok fazla şeyi değiştirmemiz isteniyor. & $3,80 \pm, 97$ &, 84 &, 71 \\
DY 5. Her zaman bir şeyi değiştirmek istiyormuşuz gibi geliyor. & $4,26 \pm 1,15$ &, 71 &, 51 \\
DY 6. Değişmeden önce bir istikrar dönemi görmek istiyorum. & $4,13 \pm 1,03$ & &, 901 \\
\hline Değişim Yorgunluğu Ölçeği & &, 84 & \\
Cronbach-alpha Güvenirlik Katsayısı & & 4,038 & \\
Spearman-Brown Güvenirlik Katsayısı & & 67,29 &, 000 \\
Öz Değer & &, 88 & \\
Açıklanan Varyans (\%) & & & \\
Barttlet'in Küresellik Testi p değeri: & & \\
Kaiser-Mayer-Olkin (KMO) & &
\end{tabular}

SS: Standart Sapma

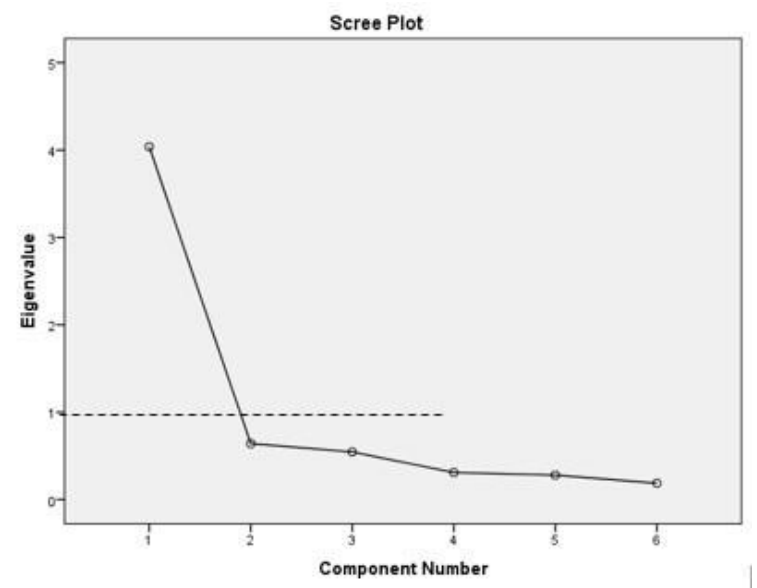

Şekil 1. Değişim Yorgunluğu Ölçeği'nin Yamaç Eğim Grafiği

Açılayıcı faktör analizinden sonra ölçeğin tek boyutlu yapısı DFA ile test edildi. DFA'ya geçilmeden önce verilerin normal dağılımı test edilmiştir. Değişkenlere ait basıklık (kurtosis) ve çarpıklık (skewness) değerlerinin \pm 1 değerleri arasında ve çoklu basıklık kritik değerinin (multivariate kurtosis critical value) 10 'un altında $(4,324)$ olduğu görülmüştür. $\mathrm{Bu}$ sonuçlara göre verilerin normal dağıldığ söylenebilir (16). Veriler çok değişkenli normal dağılım gösterdiği için tahmin yöntemi olarak en çok olabilirlik yöntemi kullanılmıştır. Çalışmada maddelerin standardize regresyon katsayılarına ve anlamlılık düzeylerine bakılmıştır. Standardize regresyon katsayılarının $(\beta 1:, 85$, t: 9,$25 ; \beta 2:, 89$, t: 9,$48 ; \beta 3:, 78$, t: 8,$75 ; \beta 4$ : $, 67, \mathrm{t}: 7,94 ; \beta 5:, 77, \mathrm{t}: 8,91 ; \beta 6:, 63, \mathrm{t}: 9,25)$ , 50 'nin üzerinde olduğu ve $p$ değerlerinin 
tamamının anlamlı $(\mathrm{p}<, 01)$ olduğu belirlenmiştir.

Araştırmada, model uyum değerleri olarak; $\chi^{2}$ / df (serbestlik derecesi), tahmin hatalarının ortalamasının karekökü (Root Mean Square Error of Approximation-RMSEA), karşılaştırmalı uyum indeksi (Comparative Fit Index-CFI), fazlalı uyum indeksi (Incremental Fit Index-IFI), iyilik uyum indeksi (Goodness of Fit Index-GFI), hata kareleri ortalamasının karekökü (Root Mean Square Residual-SRMR) ve normlaştırılmış uyum indeksi (Normed Fit Index-NFI) değerlerine bakılmıştır. Uyum iyiliğgi indekslerine bakildıktan sonra modifikasyon (düzeltme) indeksleri incelenmiştir. Araştırmada kovaryanslara ilişkin düzeltme indeks değerlerinden yola çıkarak gerekli düzeltmeler yapılmıştır. Kovaryanslara ilişkin düzeltmelerde modelde yer alan değişkenlerin denekler tarafindan neredeyse aynı şekilde algılanan maddelerin birleştirilmesini, yani birbirleriyle ilişkilendirilmesini sağlar (16). Düzeltme yapılırken dikkat edilmesi gereken hususlardan biri düzeltmelerin teker teker yapılması ve eşik değerlere ulaşıldığında başka düzeltme yapılmamasıdır. Ayrıca 6 ile 11 maddeden oluşan ölçeklerde 2'den fazla düzeltme yapılmaması önerilmektedir (16, 21). Ölçekte yer alan DY1- DY3 maddeleri ile DY4 - DY5 maddelerinin birleşim modifikasyonları yapıldıktan sonra ölçeğin beklenen uyum değerlerinde olduğu tespit edilmiştir.

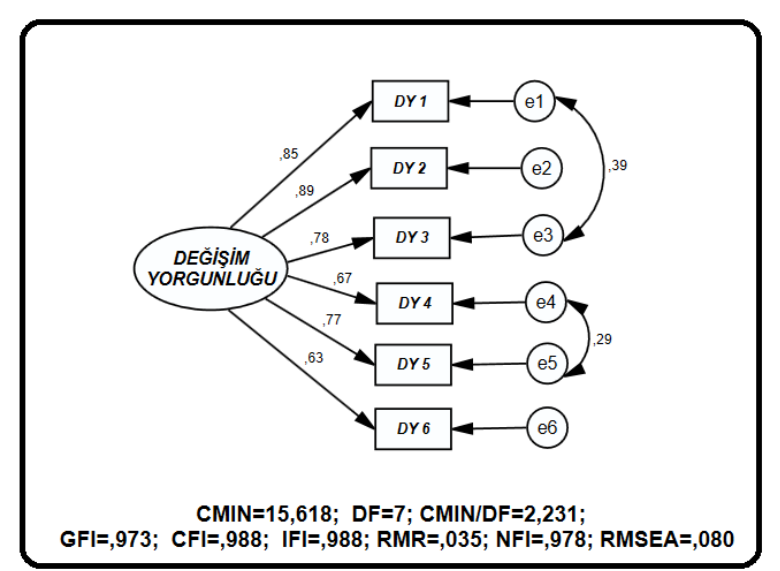

Şekil 2. Değişim Yorgunluğu Ölçeği'nin Doğrulayıcı Faktör Analizi

Tablo 5. Modele Ait Uyum İndeks Değerleri

\begin{tabular}{|c|c|c|c|c|c|c|c|c|c|}
\hline Uyum Índeksleri & $\chi 2(\mathrm{CMIN})$ & df & $\chi 2 / \mathrm{df}$ & CFI & IFI & GFI & RMR & RMSEA & NFI \\
\hline Kabul Edilebilir & & & $3>-5 \leq$ & $\geq, 90$ & $\geq, 90$ & $\geq, 90$ & $\leq, 08$ & $\leq, 08$ & $\geq, 90$ \\
\hline İyi Uyum & & & $\leq 3$ & $\geq 95$ & $\geq, 95$ & $\geq 95$ & $\leq, 05$ & $\leq, 05$ & $\geq, 95$ \\
\hline Ölçek Değerleri & 15,618 & 7 & $2,23^{\mathrm{a}}$ &, $98^{\mathrm{a}}$ &, $98^{\mathrm{a}}$ &, $97^{\mathrm{a}}$ &, $03^{\mathrm{a}}$ &, $080^{\mathrm{b}}$ &, $97^{\mathrm{a}}$ \\
\hline
\end{tabular}

Uyum iyiliği değerleri Gürbüz (2019) ve Meydan ve Şeşen (2011) kaynağından alınmıştır (16, 21)

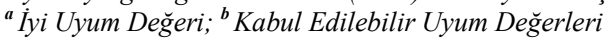

Ölçeğin son şekline ait DFA modeli Şekil 2'de gösterilmiştir. Uyum iyiliği indeksleri için "kabul edilebilir" değeler, "iyi uyum" değerleri ve modele ait uyum değerleri tablo halinde verilmiştir (Tablo 5). Analiz sonuçlarına göre RMSEA değerinin "kabul edilebilir" uyum $(, 080)$ düzeyinde, diğer indeks değerlerinin $(\chi 2 / \mathrm{df}: 2,23$; GFI: ,973; 
CFI: ,988; IFI: ,988; RMR: ,035 ve NFI: ,978) ise "iyi uyum" düzeyinde olduğu belirlenmiştir. $\mathrm{Bu}$ sonuçlara göre Değiş̧im Yorgunluğu Ölçeği'nin tek faktörlü olarak doğrulandığı söylenebilir.

\section{Tartışma ve Sonuç}

Değişim Yorgunluğu Ölçeği'nin Türkçe versiyonunun geçerlilik ve güvenirliğini test amacıyla yapılan ve sağlı çalışanları üzerinde gerçekleştirilen bu çalışmada ölçeğin güvenirliğinin yüksek olduğu, dil ve kapsam geçerliliğine sahip olduğu ve tek boyutlu olarak yapı geçerliliğini sağladığı görülmüştür. Ölçeğin Türkçe versiyonunun güvenirlik ve geçerlilik çalışmasının Türkiye'de eğitim çalışanları üzerinde daha önce yapıldığı görülmüştür (1). Sağlık kurumları birçok farklı meslek grubunun (doktor, hemşire, teknisyen, memur vb.) bir arada faaliyet gösterdiği kurumlardır. Bu kurumlar, merkezi yönetimin talep ettiği değişimleri yerine getirmek zorundadır. Ayrıca teknolojik gelişmeler, hizmeti talep edenlerin beklentilerinde değişimler, kurum yöneticilerinin süreçleri iyileştirme ve maliyetleri azaltma çabası, hasta ve çalışan güvenliği ile kalite gibi hizmet etkinliğini ve verimliliğini arttırma süreçlerinde sık sık yeni prosedürlerin hayata geçirilmesi, sağllk kurumlarında değişimleri kaçınılmaz kılmaktadır. Belirtilen nedenlerle tüm çalışanlar çok fazla değişime maruz kalmaktadır. $\quad \mathrm{Bu}$ durumun sağlık çalışanlarında değişim yorgunluğu meydana getirebileceği söylenebilir. Ancak, sağlik çalışanları üzerinde gerçekleştirilen ve Değişim Yorgunluğu Ölçeği'nin geçerli ve güvenirliği değerlendiren herhangi bir çalışmaya rastlanılmamıştır. $\mathrm{Bu}$ bakımdan çalışma sonuçlarının alan yazına önemli katkısının olacağı düşünülmektedir.

Ölçeğin dil geçerliliğini tespit etmek için; ölçek hem Türkçe hem de İngilizce dillerine hâkim iki akademisyen tarafından Türkçeye çevrilmiştir. Başka bir akademisyen tarafindan geri İngilizce çevirisi yapılmıştır. Orijinal metin ile çeviri yapılan metin karşılaştırılmış ve aralarında anlam açısından fark olmadığ 1 görülmüştür. Maddelerin anlaşılabilirliğini test etmek için ölçeğin son hali 15 sağlık çalışanı üzerinde uygulanmış ve soruların anlaşılır olduğu belirlenmiştir. Kapsam geçerliğinin sınamak için 7 akademisyenin görüşlerine başvurulmuş ve akademisyenlerin yarısından fazlası tüm maddeler için "gerekli" olduğu şeklinde değerlendirmede bulunmuşlardır. Sonuç olarak, ölçeğin dil ve kapsam geçerliliğine sahip olduğu görüldükten sonra güvenirlik ve yapı geçerliliğine ilişkin analizler yapılmıştır.

Analiz sonuçlarına göre ölçek maddeleri arasındaki korelasyon katsayıları ,458 -,789 arasinda ve toplam korelasyon ise ,90'in altındadır. Maddeler arasındaki ilişkinin benzer olduğu ve maddeler arasında yüksek bir korelasyonun olmadığı tespit edilmiştir. Madde çıkarımları sonrası Cronbach alfa katsayılarının (,866-,900) tüm ölçeğin Cronbach alfa katsayısının $(<, 901)$ altında olduğu ve tüm maddelerin ölçeğin bir parçası olduğu sonucuna varılmıştır.

Bernerth ve diğerleri (2011) altı maddelik Değişim Yorgunluğu Ölçeği'ne ait Cronbach alfa katsayısinı ,84, Limon (2020) ise ,86 olarak tespit etmiştir $(1,8)$. Belirtilen iki çalışmadaki ve bu çalışmadaki Cronbach alfa değerlerine bakıldığında her üç çalışmada da bu değerlerin yüksek olduğu ve ölçeğin güvenirliğinin yüksek olduğu söylenebilir. Yamaç eğim grafiği ve Kaiser kriter değeri (öz değerin 1'in üzerinde olmas1) incelendiğinde; özdeğeri 1'in üzerinde olan tek bir boyutun (öz değeri: 4,038) olduğu ve tek boyutlu olarak toplam varyansı açıklama oranının \%67,29 olduğu görülmüştür. Limon (2020) tarafindan yapılan çalışmada tek faktörlü yapının toplam varyansı açıklama oranının \%51,37 olduğu belirlenmiştir (1).

Yapılan DFA sonucu elde edilen uyum iyiliği değerleri incelendiğinde; $\chi 2 / \mathrm{df}(2,23)$, CFI $(, 98)$, IFI $(, 98)$ ve GFI $(, 97)$, RMR $(, 03)$ ve NFI $(, 97)$ değerlerinin "iyi uyum" düzeyinde, RMSA $(, 08)$ değerinin ise "kabul edilebilir" uyum düzeyinde olduğu görülmüştür. Limon (2020) tarafından eğitim kurumlarında yapılan çalışmada bu değerlerin tümünün "iyi" uyum" düzeyinde olduğu belirlenmiştir (1). Araştırma sonuçlarına göre Değişim Yorgunluğu Ölçeği'nin, kısa, tek boyutlu bir ölçüm ve değerlendirme aracı olarak kullanılabileceği değerlendirilmektedir. 
Değişim yorgunluğu, çalışanların doğrudan bilinçli bir şekilde aldıkları karardan ziyade (22), tekrarlanan değişimlere karşı bir yanıt olarak yaşanmış deneyimler ile bir yaşam biçimi haline gelebilir (8). Bunun sonucunda çalışanların değişimler ile birlikte organizasyon içerisindeki birçok uygulamaya karş1 olumsuz tutum sergilemelerine neden olabilir. Hizmet çıktıları üzerinde doğrudan etkiye sahip sağlık çalıșanlarının değișim yorgunluğu düzeyleri performanslarını düşürebilir ve bunun sonucunda tedavi süreçleri ve sağlık sonuçlarını olumsuz etkileyebilir.

Axelsson (2000), sağlik hizmetlerinde değişimin hem hızlı ve hem de süreklilik arz ettiğinin altını çizmiştir (23). Buna göre değişim kaçınılmazdır. $\mathrm{Bu}$ durumda çalışanların değişime karşı algılarının ve

\section{KAYNAKLAR}

1. Limon İ. Turkish adaptation of change fatigue scale: A study of reliability and validity. Sakarya University $J$ of Education. 2020;10: 292-311.

2. Goodstein LD, Burke WW. Creating successful organization change. Organizational Dynamics. 1991;19:5-17.

3. Quattrone P, Hopper T. What does organizational change mean? Speculations on a taken for granted category. Management Accounting Research. 2001;12:403-435.

4. Freedman M. Initiative fatigue. Strategic Change. 1992;1:89-91.

5. Lingard B, Mill M, Haye D. Teachers, school reform and social justice: Challenging research and practice. Australian Educational Researcher. 2000;27:99-115.

6. Abrahamson E. Change without pain. Harvard Business Review. 2000;78:75-79.

7. Lindsay JD, Perkins CA, Karanjikar MR. Conquering innovation fatigue: overcoming barriers to personal and corporate success. New Jersey: John Wiley \& Sons. (2009).

8. Bernerth JB, Walker HJ, Harris SG. Change fatigue development and initial validation of a new measure. Work \& Stress. 2011;25;321-337.

9. Lyle J, Cunningham C, Gray J. The new Australian curriculum, teachers and change fatigue. Australian $J$ of Teacher Education. 2014;39:45-64.

10. Zink KJ, Steimle U, Schroder D. Comprehensive change management concepts development of a participatory approach. Applied Ergonomics. 2008;39:527-538.

11. Buchanan D, Fitzgerald L, Ketley D, Gollop R, Jones JL, Lamont SS, et al. No going back: A review of the değişim yorgunluğu düzeylerinin bilinmesi önemlidir. Sağlı çalışanların değişim yorgunluğu düzeylerini belirlemek için ölçme değerlendirme araçlarına ihtiyaç bulunmaktadır. $\mathrm{Bu}$ araştırma bulguları Değișim Yorgunluğu Ölçeği'nin sağlik çalışanlarının değişim yorgunluğu düzeylerini değerlendirmek için geçerli ve güvenilir bir ölçme aracı olarak kullanılabileceğini göstermektedir.

Yapılacak çalışmalarda bu ölçek ile sağlık çalışanların değişim yorgunluğu düzeyi değerlendirilebileceği gibi, meslek gruplarına göre değişim yorgunluğu düzeylerinin karşılaş̧tırılması, değişim yorgunluğu ile iş tatmini, performans, stres, sunulan hizmet kalitesi, işten ayrılma niyeti vb. ilişkisinin incelenmesi önerilmektedir. literature on sustaining organizational change. International Journal of Management Reviews. 2005;7:189-205.

12. McMillan K, Perron A. Nurses amidst change: The concept of change fatigue offers an alternative perspective on organizational change. Policy, Politics, \& Nursing Practice. 2013;14:26-32.

13. Camilleri J, Cope, V, \& Murray, M. Change fatigue: The frontline nursing experience of large-scale organisational change and the influence of teamwork. $J$ of Nursing Management. 2019;27: 655-660.

14. Smollan R. Causes of stress before, during and after organ- isational change: A qualitative study. J of Organisational Change Management. 2015; 28:301314.

15. Johnson K. The dimensions and effects of excessive change. J of Organisational Change Management. 2016;29:445-459.

16. Gürbüz S. (2019), AMOS ile yapısal eşitlik modellemesi. Ankara: Seçkin Yayıncılık.

17. Lawshe $\mathrm{CH}$. A quantitative approach to content validity. Personnel Psychology. 1975;28:563-575.

18. Alpar, R., Spor sağlık ve eğitim bilimlerinden örneklerle uygulamalı istatistik ve geçerlik güvenirlik. 2. Bask1. Ankara: Detay Yayıncılık. (2014)

19. Sürücü L, Maslakçı A. Validity and reliability in quantitative research. Business \& Management Studies. 2020;8:2694-2726.

20. Büyüköztürk Ş. Sosyal bilimler için veri analizi el kitabı. Ankara: Pegem Akademi. (2013).

21. Meydan $\mathrm{CH}$, Şeşen H. (Yapısal eşitlik modellemesi AMOS uygulamaları. Ankara: Detay Yayıncilık. 2011), 
22. Hansson A, Vingard E, Arnetz BB, Anderzen I. Organisational change, health, and sick leave among health care employees: A longitudinal study measuring stress markers, individual, and work site factors. Work \& Stress. 2008; 22 :69-80.

23. Axelsson R. The organizational pendulum: Healthcare management in Sweden 1865-1998. Scandinavian J of Public Health. 2000; 28: 47-53.

๑Copyright 2021 by Osmangazi Tıp Dergisi - Available online at tip.ogu.edu.tr ๑Telif Hakkı 2021 ESOGÜ Tıp Fakültesi - Makale metnine dergipark.org.tr/otd web sayfasından ulaşılabilir. 